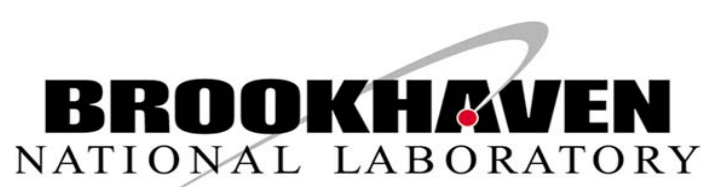

BNL-113247-2016-JA

\title{
Metrics for the Technical Performance Evaluation of Light Water Reactor Accident-Tolerant Fuel
}

\author{
Shannon M. Bragg-Sitton, Michael Todosow, Robert Montgomery, \\ Christopher R. Stanek, Rose Montgomery, and W. Jon Carmack
}

Submitted to Nuclear Technology

November 18, 2016

\section{Nuclear Science and Technology Department}

\author{
Brookhaven National Laboratory
}

\section{U.S. Department of Energy \\ Office of Science, Office of Nuclear Physics}

\footnotetext{
Notice: This manuscript has been authored by employees of Brookhaven Science Associates, LLC under Contract No.DE-SC0012704 with the U.S. Department of Energy. The publisher by accepting the manuscript for publication acknowledges that the United States Government retains a non-exclusive, paid-up, irrevocable, world-wide license to publish or reproduce the published form of this manuscript, or allow others to do so, for United States Government purposes.
} 


\section{DISCLAIMER}

This report was prepared as an account of work sponsored by an agency of the United States Government. Neither the United States Government nor any agency thereof, nor any of their employees, nor any of their contractors, subcontractors, or their employees, makes any warranty, express or implied, or assumes any legal liability or responsibility for the accuracy, completeness, or any third party's use or the results of such use of any information, apparatus, product, or process disclosed, or represents that its use would not infringe privately owned rights. Reference herein to any specific commercial product, process, or service by trade name, trademark, manufacturer, or otherwise, does not necessarily constitute or imply its endorsement, recommendation, or favoring by the United States Government or any agency thereof or its contractors or subcontractors. The views and opinions of authors expressed herein do not necessarily state or reflect those of the United States Government or any agency thereof. 


\title{
Metrics for the Technical Performance Evaluation of Light Water Reactor Accident-Tolerant Fuel
}

\author{
Shannon M. Bragg-Sitton, ${ }^{\mathrm{a} *}$ Michael Todosow, ${ }^{\mathrm{b}}$ Robert Montgomery, ${ }^{\mathrm{c}}$ Christopher R. Stanek, ${ }^{\mathrm{d}}$ \\ Rose Montgomery, ${ }^{\mathrm{e} \dagger}$ and W. Jon Carmack ${ }^{\mathrm{a}}$ \\ ${ }^{a}$ Idaho National Laboratory, Idaho Falls, Idaho \\ ${ }^{b}$ Brookhaven National Laboratory, Upton, New York \\ ${ }^{c}$ Pacific Northwest National Laboratory, Richland, Washington \\ ${ }^{d}$ Los Alamos National Laboratory, Los Alamos, New Mexico \\ ${ }^{e}$ Tennessee Valley Authority, Knoxville, Tennessee
}

Received November 17, 2015

Accepted for Publication February 2, 2016

http://dx.doi.org/10.13182/NT15-149

\begin{abstract}
The safe, reliable, and economic operation of the nation's nuclear power reactor fleet has always been a top priority for the nuclear industry. Continual improvement of technology, including advanced materials and nuclear fuels, remains central to the industry's success. Enhancing the accident tolerance of light water reactors (LWRs) became a topic of serious discussion following the 2011 Great East Japan Earthquake, resulting tsunami, and subsequent damage to the Fukushima Daiichi nuclear power plant complex. The overall goal for the development of accident-tolerant fuel (ATF) for LWRs is to identify alternative fuel system technologies to further enhance the safety, competitiveness, and economics of commercial nuclear power. Designed for use in the current fleet of commercial LWRs or in reactor concepts with design certifications (GEN-III+), fuels with enhanced accident tolerance would endure loss of active cooling in the reactor core for a considerably longer period of time than the current fuel system while maintaining or improving performance during normal operations. The complex multiphysics behavior of LWR nuclear fuel in the integrated reactor system makes defining specific material or design improvements difficult; as such, establishing desirable performance attributes is critical in guiding the design and development of fuels and cladding with enhanced accident tolerance. Research and development of ATF in the United States is conducted under the U.S. Department of Energy (DOE) Fuel Cycle Research and Development Advanced Fuels Campaign. The DOE is sponsoring multiple teams to develop ATF concepts within multiple national laboratories, universities, and the nuclear industry. Concepts under investigation offer both evolutionary and revolutionary changes to the current nuclear fuel system. This paper summarizes the technical evaluation methodology proposed in the United States to aid in the optimization and prioritization of candidate ATF designs.
\end{abstract}

Keywords - Accident-tolerant fuel, advanced LWR fuel, advanced nuclear fuel.

Note - Some figures may be in color only in the electronic version.

\section{INTRODUCTION}

The safe, reliable, and economic operation of the nation's nuclear power reactor fleet has always been a top priority for the nuclear industry. Continual improvement

*E-mail: Shannon.Bragg-Sitton@inl.gov

${ }^{\dagger}$ Current address: Oak Ridge National Laboratory, Oak Ridge, Tennessee of technology, including advanced materials and nuclear fuels, remains central to the industry's success. Decades of research combined with continual operation have produced steady advancements in technology and have yielded an extensive amount of data, experience, and knowledge on light water reactor (LWR) fuel performance under both normal and accident conditions. Enhancing the accident tolerance of LWRs became a topic 
of serious discussion following the 2011 Great East Japan Earthquake, resulting tsunami, and subsequent damage to the Fukushima Daiichi nuclear power plant complex. As a result of direction from the U.S. Congress, the U.S. Department of Energy (DOE) Office of Nuclear Energy (DOE-NE) initiated an accident-tolerant fuel (ATF) development program within the Fuel Cycle Research and Development (FCRD) Advanced Fuels Campaign (AFC). In addition, the Nuclear Energy Advanced Modeling and Simulation program is developing advanced fuel performance models for ATF designs, which will be applied in evaluating concepts against the metrics defined in this paper.

The commercial nuclear power industry has matured and optimized its fuel technology and has an excellent safety and operational record. The currently used $\mathrm{UO}_{2}-$ zirconium alloy fuel system meets all performance and safety requirements while keeping nuclear energy an economically competitive clean-energy alternative for the United States. With the exception of a few extremely rare events, the current fuel system has performed exceptionally well.

The primary goal of ATF development is to identify alternative fuel system technologies that may further enhance the safety, competitiveness, and economics of commercial nuclear power. Additionally, the development of enhanced fuel system alternatives supports the sustainability of nuclear power, allowing continued utilization of this clean, low- $\mathrm{CO}_{2}-$ emitting option for electrical power generation in the United States and internationally. To demonstrate the benefit of the proposed ATF concepts, it is useful to evaluate them against the current optimized fuel design and its operational, economic, and safety requirements. The overall fuel cycle must also be considered, particularly for concepts that represent a significant departure from the current technology.

The complex multiphysics behavior of LWR nuclear fuel makes defining specific material or design improvements challenging. However, establishing desirable performance attributes is critical in guiding the selection and development of fuels and cladding with enhanced accident tolerance. A basic tenet of ATF designs is that they should endure the loss of active cooling in the reactor core for a considerably longer period of time than the current fuel system - depending on the LWR system and accident scenario-while maintaining or improving fuel performance during normal operations. Key requirements defined for advanced fuels relate to the nuclear fuel performance, cladding performance, and adherence to overall system constraints.

A technical evaluation methodology is proposed within the United States to aid in the optimization and prioritization of candidate ATF designs. A complete description of the proposed metrics and associated sensitivity studies is provided in Ref. 1. This methodology is also considered as a starting point for a similar international document that will be produced by the Nuclear Energy Agency (NEA) Expert Group on Accident Tolerant Fuel for LWRs (established in 2014 under the NEA Nuclear Science Committee). As used herein, "metrics" describes a set of technical bases that will be used to objectively evaluate multiple concepts relative to a common baseline and to one another. The proposed metrics will be applied to assess the ability of each concept to meet performance and safety goals relative to the current $\mathrm{UO}_{2}$ zirconium alloy system.

Evaluation of anticipated benefits will be based on existing characterization and test data as well as reasonable extrapolations of that data based on modeling and simulation. Potential vulnerabilities will also be scored based on known or anticipated operational vulnerabilities; a penalty will also be assessed when information regarding an important performance parameter is as yet unknown. The resultant ranked evaluation may then be used to inform prioritization of the candidate ATF systems, such that the most promising option(s) can continue to be developed.

This paper provides an overview of the considerations, constraints, evaluation methods, and metrics being applied to concepts as they progress through the ATF development program.

\section{ATF ATTRIBUTES AND CONSTRAINTS}

With the assistance of the nuclear energy community, the FCRD AFC has embarked on an aggressive schedule for ATF development. The program is in the early phases of research and development (R\&D) and is currently supporting the investigation of a number of candidate technologies that may further improve the fuel system. This section describes the desired ATF attributes, criteria, and some regulatory considerations for implementation, followed by the phased approach to development and integration of ATF in the commercial power industry.

\section{II.A. Design Constraints}

Any new fuel concept proposed for enhanced accident tolerance must be compliant with and evaluated against current design, operational, economic, and safety requirements. The constraints associated with commercial nuclear fuel development and deployment that are applied to ATF designs include the following:

1. backward compatibility: compatible with existing fuel-handling equipment, fuel rod or assembly geometry, and coresident fuel in existing LWRs

2. operations: maintains or extends plant operating cycles, reactor power output, and reactor control 
3. safety: meets or exceeds current fuel system performance under normal, anticipated operational occurrences (AOOs), design-basis accident (DBA), and beyond design-basis accident (BDBA) conditions

4. front end of the nuclear fuel cycle: adheres to regulations and policies, for both the fuel fabrication facility and the operating plant, with respect to technical, regulatory, equipment, and fuel performance considerations

5. back end of the nuclear fuel cycle: cannot degrade the storage (wet and dry) and repository performance of the fuel (assuming a once-through fuel cycle); should consider possible future transition to a closed fuel cycle

6. economics: maintains economic viability with respect to additional costs (e.g., fabrication) and potential cost reductions realized through improved performance (higher burnup for extended cycles and power upgrades, reduced waste) or increased safety margin.

\section{II.B. ATF Attributes}

Fuels with enhanced accident tolerance are defined as fuels that can tolerate a severe loss of active cooling in the reactor core for a considerably longer time period than the current $\mathrm{UO}_{2}$-zirconium alloy fuel system, while maintaining or improving the fuel performance during normal operations, operational transients, and DBAs. The desired ATF improvement areas, as illustrated in Fig. 1, highlight the performance attributes to be modified to increase accident tolerance of the fuel system. These include reduced steam reaction kinetics (reaction rate and heat of reaction), lower hydrogen generation rate (or generation of other combustible gases), and reduction of the initial stored energy in the core. The desired behaviors should be accomplished while maintaining or improving cladding and fuel thermomechanical performance, fuel-clad interaction compliance, and fission product evolution, retention, and possible dispersal. Targeting improvements in these attributes provides guidance in establishing the critical parameters that must be considered in the development of fuels and cladding with enhanced accident tolerance. A set of qualitative performance metrics derived from these desired attributes across all fuel performance regimes aids in concept optimization and later prioritization of candidate ATF system designs on a more quantitative basis.

Candidate fuel systems must first adhere to the principle "do no harm," meaning that the fuels must, under all operating conditions, perform at least as well as or better than the current fuel system. As such, a candidate fuel should preserve or improve upon
1. burnup limits/cycle length (while maintaining criticality and fuel performance)

2. operational parameters (power distribution, peaking factors, safety margins, etc.)

3. reactivity coefficients and control parameters (shutdown margin, rod worths)

4. handling, transportation, and storage (consideration of fuel isotopics, handling dose, and mechanical integrity)

5. compatibility with existing infrastructure (e.g., fabrication facilities, loading, in-core operations, postirradiation handling and storage, etc., necessary to maintain acceptable economics).

To be considered accident tolerant, the fuel system must additionally provide improved response to AOOs, DBAs [reactivity initiated accidents (RIAs), loss-ofcoolant accidents (LOCAs), and station blackout], and BDBAs relative to the $\mathrm{UO}_{2}$-zirconium alloy system.

While desirable, it is likely impossible to improve performance for all of the areas summarized in Fig. 1 with a single ATF concept that is applicable to both pressurized water reactors (PWRs) and boiling water reactors (BWRs), respectively. Hence, the leading design objectives for ATF provide guidance to fuel design after first applying the practical constraints for use of the candidate design in a currently operating LWR. The leading objectives can be summarized as follows:

1. Maintain or improve upon the thermal, mechanical, and chemical properties observed for the current state-of-the-art fuel systems.

2. Provide accident-tolerant improvements that increase coping time (or grace period) under severe accident scenarios.

a. Increase the time before the onset of core melt, during which additional recovery actions can be made to halt the accident progression.

b. Reduce the impact of a severe accident by reducing core damage frequency, maintaining coolable geometry, and reducing combustible gas production and the amount of radioactive materials potentially released.

3. Offer the capability for power uprate and increased burnup to allow an economic case to be made for adoption of the new fuel system. ${ }^{\mathrm{a}}$

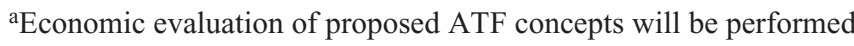
separately from the technical evaluation. 


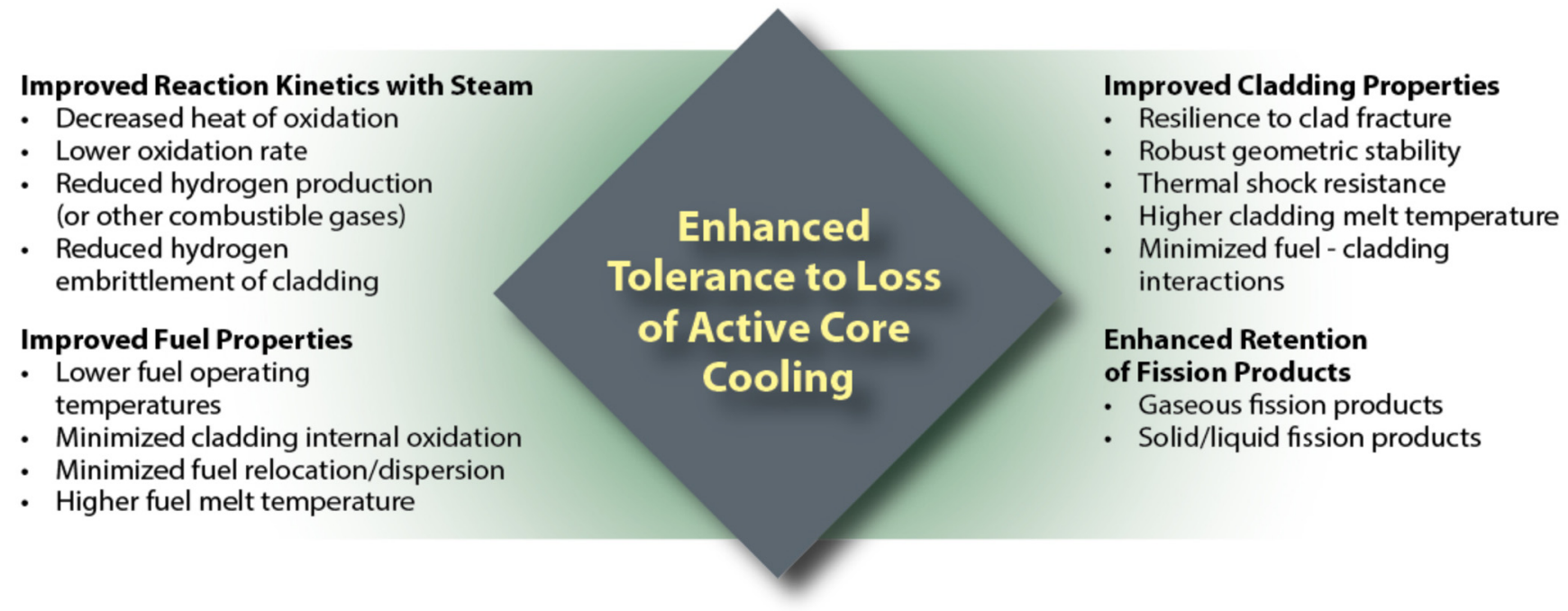

Fig. 1. Key considerations in establishing ATF attributes.

\section{II.C. "Go/No-Go" Criteria}

A large number of properties and performance parameters must be considered in fuel development. Fuel performance is the result of a complex system with interaction between the components of the fuel, cladding, reactor configuration, and protection systems. Fuel system performance cannot be evaluated in isolation, and these concepts currently are intended for use in commercial power plants that have fixed designs. Therefore, some "go/no-go" criteria must be established for concept fuel systems prior to defining more specific performance targets. Briefly stated, these include the following:

1. The fuel design must meet current LWR geometric constraints (e.g., outer assembly/bundle envelope preserved for compatibility with core geometry) without adversely affecting assembly thermal hydraulics.

2. The fuel must have a quantifiable benefit under accident scenarios (e.g., longer time to onset of fuel melt under reference accident scenarios) relative to the current fuel system to be deemed accident tolerant.

3. Reactivity feedback coefficients must be similar in magnitude and parametric behavior to the reference $\mathrm{UO}_{2}$-zirconium alloy system to ensure backward compatibility in existing reactors. Reactivity coefficients for candidate fuels must not reduce the safety of the reactor system or the safety margin and should fall within the existing safety envelope for $\mathrm{UO}_{2}-\mathrm{Zr}$ fuels.

a. In some cases the calculated moderator temperature coefficients can be slightly positive (for current fuel systems) at the beginning of life (BOL) with high soluble boron concentration. It is possible that the moderator temperature coefficient may also be slightly positive for some candidate ATFs under similar conditions.

b. Reactivity coefficients that are more negative than the reference $\mathrm{UO}_{2}$-zirconium alloy system may be problematic if they interfere with shutdown margin or system stability.

4. The fuel must maintain or extend current cycle length and power output at allowable enrichment levels (increased cycle length, number of fuel batches in the core management scheme, and power density may be desirable but not required).

A concept that fails to meet one of these criteria would be omitted from further consideration. For example, a fuel concept enrichment requirement of $20 \mathrm{wt} \%$ or higher (above the low-enriched-uranium (LEU) limit], as determined by neutronic calculations, would be "no-go." Exceeding the LEU limit of $20 \mathrm{wt} \%$ enrichment equates to a vulnerability that cannot be overcome, hence removing the concept from consideration. A required enrichment of $<5 \mathrm{wt} \%$ would be acceptable, while 5 to $20 \mathrm{wt} \%$ would be assigned an increasing vulnerability (or risk factor) as the enrichment requirement increases. Note, however, that fuel fabrication facilities are currently licensed to $5 \mathrm{wt} \%$ enrichment. Benefit and vulnerability scores are discussed in detail in Sec. IV.B.

\section{II.D. Regulatory Considerations}

Because of the enforced compatibility constraints for the current ATF development, the fundamental regulatory criteria for ATF concepts are likely similar to the key reactor safety parameters that apply to the reference 
$\mathrm{UO}_{2}$-zirconium alloy fuel system: lattice and full-core reactivity coefficients, thermal margin, full-core hot spot, and hot channel factors during normal operation (e.g., $F_{q}$ and $F_{\Delta h}$ ), and potential challenges in fuel management. However, the applicability of existing regulatory limits to the fuel system concepts must be demonstrated. For example, it is likely that for some concepts, reasonable thermal limits will differ significantly from the current $\mathrm{UO}_{2}-$ zirconium alloy system due to the temperatures at which eutectics could form between the proposed fuel and cladding, the impact of such eutectics on the fuel and cladding melt temperatures, etc. The expected performance of each conceptual fuel system must be examined under all postulated normal operation and accident conditions throughout its intended lifetime (e.g., at high burnup) to ensure that its performance provides the desired level of protection. Limits originally set for zirconium alloys may not be applicable to new fuel designs or to the operation of the current fuel system to higher burnup. Effort should be expended to search the regulatory issue space for the limiting case for each fuel concept considered. ${ }^{2}$ Even conceptual fuel systems utilizing zirconium-based alloys will require rigorous evaluation if they are to be used in conjunction with new fuels or operated to higher burnup.

\section{ATF DEVELOPMENT}

The ATF development effort adopts a three-phase approach to commercialization. The approximate time frame for each phase is noted, where FY is the U.S. government fiscal year (October through September).

Phase 1: Feasibility Assessment and PrioritizationFY2012 to 2016

Feasibility assessment focuses on obtaining data from initial small-scale and phenomenological testing in order to conduct an informed prioritization of concepts. This work includes activities such as laboratory-scale experiments (e.g., fabrication, preliminary irradiation, and material properties' measurements); fuel performance code updates for specific concepts, applying measured properties and behavior data; and analytical assessment of economic, operational, safety, fuel cycle, and environmental impacts. Existing fuel performance codes will be used during this phase to the degree the relevant fuel and cladding property measurements and/or models are available. Analytical assessments will be performed to evaluate promising concepts against the defined attributes for ATF. Concepts demonstrating promising technical performance and feasible economics (considering the full life cycle of the fuel) will progress to phase 2 , pending funding availability.
Phase 2: Development and Qualification-FY2017 to 2022

During this phase, the fabrication process will expand to use industrial-scale fabrication methods, and fabrication of lead fuel rods (LFRs) or lead fuel assemblies (LFAs) will occur. Test reactor irradiation using long rodlets [ $\sim 0.9$-m-long (36-in.-long) fuel column] will cover fabrication variations, temperature, and linear heatrate limits. Characterization, postirradiation examination (PIE), and the development of an advanced fuel performance code applicable to the specific fuel system concept will be part of the qualification process for a LFR. Sufficient testing must be completed to establish a statistically significant database. By 2018 a transient testing capability in a water loop will also need to be established. Transient experiments on unirradiated and irradiated rodlets are planned to begin in approximately FY2018 to establish fuel-failure modes and failure margins. At the end of this phase, LFRs or LFAs will be fabricated, and the safety basis for irradiation in a commercial reactor will be completed. The overall requirements for the scope of the LFR/LFA testing will be established during the development phase. If the assembly design differs substantially from that of currently used $\mathrm{UO}_{2}$-zirconium alloy assemblies, qualification will likely require testing of a full assembly. To allow for testing in existing commercial reactors, the outer envelope of the assembly is required to be the same as that of existing assemblies. Any changes to the hydraulic characteristics, e.g., rod outer diameter or pitch, would require additional testing. If the assembly design is similar to that of the current design, a few LFRs incorporated into a fuel assembly containing $\mathrm{UO}_{2-}$ zirconium alloy rods may be sufficient for fuel system qualification. The irradiation and subsequent PIE of the LFRs/LFAs will complete the demonstration phase for LWR fuels with enhanced accident tolerance.

\section{Phase 3: Commercialization-FY2022 and Beyond}

Partial-core (region-sized) reloads will be demonstrated in a commercial LWR to verify the performance observed for the LFRs and LFAs and to provide confirmatory data for final licensing of the product. The commercialization phase will entail the establishment of commercial fabrication capabilities and the transition of LWR cores to the new fuel. This phase is envisioned to be primarily a commercial activity performed by industry.

The three development phases described roughly correspond to the technology readiness levels (TRLs) defined for nuclear fuel development. ${ }^{3}$ TRLs 1, 2, and 3 roughly correspond to the proof-of-concept stage (phase 1), TRLs 4,5 , and 6 roughly correspond to the proof-of-principle stage (phase 2), and TRLs 7, 8, and 9 roughly correspond 
to the proof-of-performance stage (phase 3). Phase 3 is sometimes referred to as commercialization, which includes commercial-scale demonstration of the licensed fuel assembly (TRL 7), completion of a full-core conversion to the new licensed fuel (TRL 8), and routine operations with the new fuel (TRL 9). The DOE ATF development program is currently conducting phase 1 activities. The evaluation metrics outlined in this paper will be applied at the end of phase 1 to determine/inform which fuel system concept (or concepts) has (have) the greatest potential for success as a commercial LWR fuel having enhanced, accident-tolerant characteristics.

\section{III.A. Development Steps and Evaluation}

The development steps described in Fig. 2 (numbered 1 through 8 ) address the full scope of activities that should be considered in evaluating the feasibility of ATF concepts. Carrying out all the indicated steps can require significant investment of time and resources; however, the level of fidelity of the evaluation results is dependent upon the information developed during these activities, and it is recommended that as many as possible be completed. Following the first phase in the ATF evaluation process (TRLs 1, 2, and 3), an independent technical review is performed before the concept is advanced to the next step (see Sec. IV.B).

\section{III.B. Phase 1: Feasibility Assessment (TRLs 1, 2, and 3)}

Step 1, "Preliminary Screening," describes the preliminary screening analyses that candidate designs are subjected to in order to assess their performance under normal conditions and potential enhancements to safety under DBA and BDBA conditions in a generic PWR or BWR plant application. During the screening stage, the level of detail associated with analyses will be limited, based on the current state of knowledge for the selected concept. The level of detail may range from literature reviews and expert judgment through limited experiments and computational analyses. The goal is to have sufficient confidence in the results of the assessment (with a reasonable investment of time and resources) that a decision can be made to abandon, modify, or proceed with a concept. For further description of the corresponding fuel TRLs related to Fig. 2, see Ref. 3.

These preliminary analyses apply existing materials data, fabrication experience, and cost data. Gaps in these data are likely, requiring assumptions to be made for some of the pertinent details. Scoping analyses are expected to have relatively large uncertainty bands and should not be applied to specific design activities. The purpose in these analyses is to eliminate proposed designs that are not likely to improve upon the current fuel system performance for one or more of the key objectives and, hence, do not warrant additional investment.

Proposed designs demonstrating promise as ATF candidates via initial review are undergoing additional scoping tests and property measurement (step 2a) under DOE support and via multiple international programs. All concepts currently being developed under the DOE program have passed this initial assessment and are undergoing development and testing as described in steps $2 \mathrm{a}$ and $2 \mathrm{~b}$. This work focuses on further assessing concept viability, including detailed characterization and testing to fill data gaps as necessary to develop applicable behavioral models. For technologies deemed sufficiently mature for a concept evaluation, a systematic technology evaluation plan (STEP) document should be formalized and executed. The STEP document provides a technical road map covering relevant technology questions to mature an ATF technology from TRLs 1, 2, and 3 to TRLs 3 through 6. An ATF technology that is deemed sufficiently mature and of high potential to warrant a concept maturation study will follow a technology implementation plan (TIP) document. The TIP is a road map document to address all the relevant application technologies required for eventual fuel qualification. Several STEP and TIP documents have been prepared within the DOE ATF program for candidate technologies to clearly identify critical technology gaps and a path forward for resolving those gaps (e.g., see Refs. 4 and 5). Performance considerations intended to guide the technical review are summarized in Table I, as will be discussed in Sec. IV.A.

Step 2a, "Fundamental Scoping," and step 2b, "Preliminary Performance and Safety Assessment," include both preliminary experimental characterization and evaluation (step 2a) and preliminary core-level analyses to determine the potential impact of a proposed design on core neutronics and thermal hydraulics under normal operating conditions (step $2 b$ ). Step $2 b$ additionally includes scoping analyses for a limited set of bounding transients and accident scenarios to confirm that a proposed concept will provide benefits in coping time under accident conditions (i.e., increased coping time to allow mitigation steps to be taken), reduced accident consequences, etc., relative to the current fuel system. Assessment of the potential beneficial impact or unintended negative consequences of ATF concepts must address the obvious fuel-specific characteristics of the concept and must also address how implementation of the concept may affect overall reactor performance and safety characteristics. This assessment should include neutronics and thermal-hydraulic analyses to ensure that the reactor 


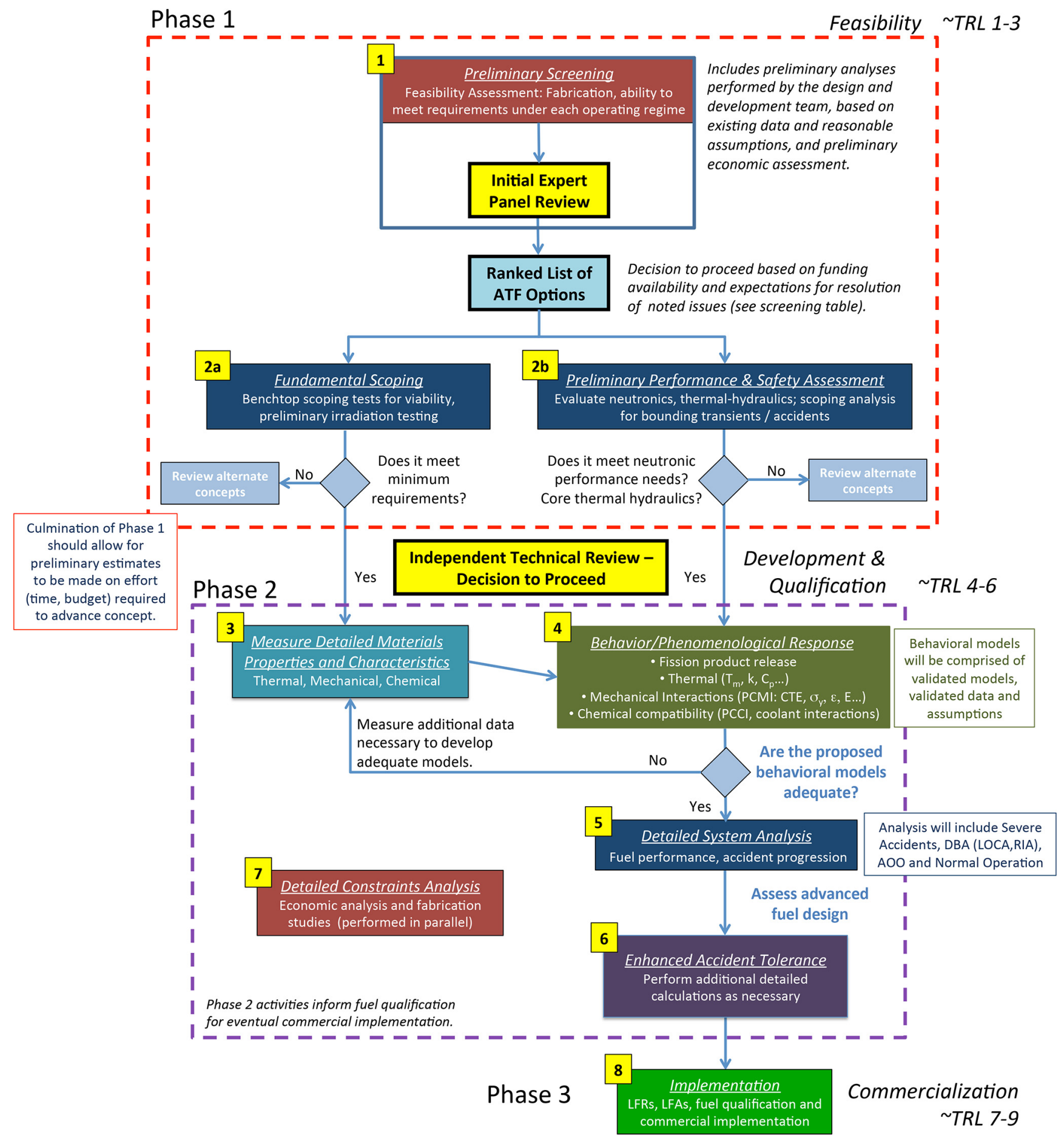

Fig. 2. Proposed ATF evaluation methodology. Preliminary concept prioritization occurs within step 1 (see step numbers 1 through 8 noted), with secondary prioritization at the end of phase 1 prior to detailed tests and development of a behavioral model.

operates as intended with the fuel system concept. Coupled thermal-hydraulic-neutronic analysis is essential in understanding the synergistic impact of the thermal properties and reactivity feedback.

At the culmination of phase 1 , concepts will be elevated to TRL $3 / 4$, and sufficient data and experience should be available to inform a preliminary estimate of the effort required, in terms of time and budget, to further advance a concept through phase 2 development to TRL 6 . The economic viability of a particular concept is critical to the adoption of a new fuel system by industry; an initial estimate of the fuel cycle costs (including fabrication costs, cost reductions 
TABLE I

Candidate Fuel System Attributes Assessment Table

\begin{tabular}{|c|c|c|c|c|c|c|c|c|}
\hline \multicolumn{3}{|c|}{ Performance Regime } & \multicolumn{3}{|c|}{ Performance Attributes } & \multicolumn{2}{|c|}{ Concept Assessment } & \multirow{2}{*}{$\begin{array}{l}\text { Concept Score } \\
\text { Justification and } \\
\text { Recommended } \\
\text { Action }\end{array}$} \\
\hline & $\begin{array}{c}\text { Regime Rank } \\
5=\text { high } \\
1=\text { low }\end{array}$ & $\begin{array}{c}\text { Fractional } \\
\text { Regime } \\
\text { Weighting }\end{array}$ & $\begin{array}{c}\text { Identifier } \\
\text { (See Table II) }\end{array}$ & $\begin{array}{c}\text { Rank } \\
(1=\text { low })\end{array}$ & $\begin{array}{l}\text { Weight } \\
\text { Within } \\
\text { Regime }\end{array}$ & $\begin{array}{l}\text { Benefit } \\
0 \text { to }+5\end{array}$ & $\begin{array}{l}\text { Vulnerability } \\
-5 \text { to } 0\end{array}$ & \\
\hline I. Fabrication & 2 & 0.13 & $\begin{array}{l}I-a \\
I-b \\
I-c \\
I-d\end{array}$ & $\begin{array}{l}3 \\
3 \\
1 \\
4\end{array}$ & $\begin{array}{l}0.27 \\
0.27 \\
0.09 \\
0.36\end{array}$ & & & \\
\hline $\begin{array}{l}\text { II. Normal operation } \\
\text { and AOOs }\end{array}$ & 4 & 0.27 & $\begin{array}{l}\text { II-a } \\
\text { II-b } \\
\text { II-c } \\
\text { II-d } \\
\text { II-e } \\
\text { II-f } \\
\text { II-g } \\
\text { II-h }\end{array}$ & $\begin{array}{l}4 \\
8 \\
5 \\
6 \\
7 \\
7 \\
7 \\
2\end{array}$ & $\begin{array}{l}0.09 \\
0.17 \\
0.11 \\
0.13 \\
0.15 \\
0.15 \\
0.15 \\
0.04\end{array}$ & & & \\
\hline $\begin{array}{l}\text { III. Postulated accidents } \\
\text { (design basis) }\end{array}$ & 4 & 0.27 & $\begin{array}{l}\text { III-a } \\
\text { III-b } \\
\text { III-c } \\
\text { III-d } \\
\text { III-e } \\
\text { III-f } \\
\text { III-g }\end{array}$ & $\begin{array}{l}6 \\
3 \\
4 \\
3 \\
4 \\
2 \\
1\end{array}$ & $\begin{array}{l}0.26 \\
0.13 \\
0.17 \\
0.13 \\
0.17 \\
0.09 \\
0.04\end{array}$ & & & \\
\hline $\begin{array}{l}\text { IV. Severe accidents } \\
\text { (beyond design basis) }\end{array}$ & 4 & 0.27 & $\begin{array}{l}\text { IV-a } \\
\text { IV-b } \\
\text { IV-c } \\
\text { IV-d } \\
\text { IV-e }\end{array}$ & $\begin{array}{l}3 \\
2 \\
4 \\
3 \\
4\end{array}$ & $\begin{array}{l}0.19 \\
0.13 \\
0.25 \\
0.19 \\
0.25\end{array}$ & & & \\
\hline $\begin{array}{l}\text { V. Used fuel storage/ } \\
\text { transport/disposition }\end{array}$ & 1 & 0.07 & $\begin{array}{l}\mathrm{V}-\mathrm{a} \\
\mathrm{V}-\mathrm{b} \\
\mathrm{V}-\mathrm{c} \\
\mathrm{V}-\mathrm{d}\end{array}$ & $\begin{array}{l}4 \\
3 \\
1 \\
3\end{array}$ & $\begin{array}{l}0.36 \\
0.27 \\
0.09 \\
0.27\end{array}$ & & & \\
\hline
\end{tabular}

due to operational enhancements, used fuel storage and handling costs, etc.) should be available at the end of phase 1 .

Assuming that a selected concept makes it through the independent technical review ("Decision to Proceed") following step 2, focused development and qualificationrelated activities will commence.

\section{III.C. Phase 2: Development and Qualification Activities (TRLs 4, 5, and 6)}

For concepts advancing past the independent technical review, additional data will be collected via both out-of-pile measurements and irradiation testing (step 3). These data will be used to develop and validate advanced behavioral models (step 4) necessary to perform more detailed fuel performance and core-level analyses for normal and off-normal conditions at higher fidelity (reduced uncertainty) than the scoping analyses in step $2 \mathrm{~b}$ allowed. The enhanced behavioral models will be applied in a more detailed system analysis (step 5) intended to evaluate the specific concept under normal and postulated accident conditions with a reduced uncertainty relative to what was possible earlier in the development (steps $2 \mathrm{a}$ and $2 \mathrm{~b}$ ). Calculations at this stage should enable quantitative estimation of the coping time under a reference severe accident scenario. Per significant discussion with the international community, coping time is specifically defined as the time, after the onset of accident conditions, to significant loss of geometry of the fuel assemblies such that the reactor core can no longer be cooled or the fuel 
TABLE II

Performance Regimes and Associated Considerations for Use with Table I

\section{Fabrication/Manufacturability}

Associated Performance Attributes

a. Manageable fissile material content

b. Compatible with large-scale production needs (material availability, fabrication techniques, waste, etc.)

c. Compatible with quality and uniformity standards

d. Ease of licensing

Considerations

Millions feet of clad/year

Approximately 300 million pellets/year

Economics: cost of raw materials and fabrication process, maximum cycle length, waste disposal

Current fabrication plant enrichment limits

II. Normal Operation and AOOs

Associated Performance Attributes

a. Utilization or burnup (12-, 18-, or 24-month cycle)

b. Thermal-hydraulic interaction

c. Reactivity control systems interaction

d. Mechanical strength, ductility (BOL and after irradiation)

e. Thermal behavior (conductivity, specific heat, melting)

f. Chemical compatibility (fuel cladding) and stability

g. Chemical compatibility with and impact on coolant chemistry

h. Fission product behavior

\section{Considerations}

Overall neutronics

Linear heat generation rate to centerline melt

Power ramp, $\sim 100 \mathrm{~W} / \mathrm{m} \cdot \mathrm{min}^{-1}$

Reduced flow [departure from nucleate boiling (DNB)]

Flow-induced vibrations

Surface roughness effects

Safe shutdown: earthquake

External pressure ( 2750 psi, 10\% above PWR design pressure)

Axial growth (less than upper nozzle gap)

\section{Postulated Accidents (Design Basis)}

Associated Performance Attributes

a. Thermal-hydraulic interaction

b. Reactivity control systems interaction

c. Mechanical strength, ductility

d. Thermal behavior (conductivity, specific heat, melting)

e. Chemical compatibility and stability (e.g., oxidation behavior)

f. Fission product behavior

g. Combustible gas production

Considerations

Prompt reactivity insertion

Post-DNB behavior $\left(T>800^{\circ} \mathrm{C}\right.$ for $\mathrm{Zr}-\mathrm{UO}_{2}$ system $)$

Loss-of-coolant conditions

Thermal shock behavior

Steam reactions $\left(\sim 1000^{\circ} \mathrm{C}+\right)$

\section{Severe Accidents (Beyond Design Basis)}

Associated Performance Attributes

a. Mechanical strength, ductility

b. Thermal behavior (conductivity, specific heat, melting)

c. Chemical compatibility and stability (including high-temperature steam interaction)

d. Fission product behavior

e. Combustible gas production 
TABLE II (Continued)
Considerations
Thermal shock behavior
Chemical reactions
Combustible gas release
Fission product release
Long-term stability in degraded state
Retention of coolable geometry

V. Used Fuel Storage, Transportation, and Disposition

Associated Performance Attributes

a. Mechanical strength, ductility

b. Thermal behavior

c. Chemical stability

d. Fission product behavior

Considerations

Handling, placement, and drying loads

Future reprocessing potential

cannot be removed from the reactor using standard tools and procedures. Results of the coping time analysis will feed into the step 6 decision point regarding the level of accident tolerance of a particular concept and will support the decision to proceed to LFR irradiation in step 8 .

Step 7 encompasses a detailed constraints analysis that will be performed during phase 2 in parallel with characterization, testing, and model development. This analysis will include detailed evaluation of the economics associated with the proposed fuel system (covering the complete fuel life cycle); challenges to fuel fabrication, with particular interest given to the required fuel enrichment determined by neutronics analysis; and potential fabrication challenges that could arise when ramping up production to the scale (e.g., cladding length) and quantities necessary for full-scale deployment in the operating LWR fleet. Constraints associated with handling, storage, transportation, and disposal of used fuel will also be addressed. Preliminary engagement of regulators will occur in parallel with phase 2 to aid future licensing activities.

\section{ATF TECHNICAL EVALUATION AND METRICS}

The term "metrics" describes a set of technical bases by which multiple concepts can be objectively evaluated against a common baseline and against one another. In some cases this may equate to a specific quantitative target value for selected properties or behaviors. Metrics can also describe a clear technical methodology for evaluation that can be used to rank concepts. Because of the complex multiphysics behavior of nuclear fuel and the large set of performance requirements that must be met, the latter definition is adopted for the evaluation of ATF concepts. Numerous international experts have been consulted in the definition of performance metrics and the associated approach to ATF design, optimization, and evaluation to enable the prioritization of near-term and long-term concepts..$^{6-8}$

The technical evaluation approach described here was compiled beginning with the collected guidance on qualitative ATF metrics. ${ }^{6-8}$ Detailed evaluation of each concept will gauge its ability to meet performance and safety goals relative to the current $\mathrm{UO}_{2}$-zirconium alloy system and relative to one another. Further, a ranked evaluation will enable the continued development of the most promising ATF design concepts given budget and time constraints, with a goal of inserting one or more concepts as a LFR/LFA in a commercial LWR by 2022.

\section{IV.A. ATF Concept Screening}

Table I is a proposed screening table to be used in the evaluation and assessment of candidate fuel systems. The attributes defined in Table I correspond to a complete fuel system (fuel plus cladding) over the entire fuel life cycle (fabrication to operation to used fuel management). The listed attributes are intended to apply to both PWR and BWR plants, although some of the noted "Considerations" (Table II) include constraints that are specific to one system or the other. Table I is designed to be applicable to a candidate fuel system at all stages of development. Initial review of a concept may rely on analyses and scoping studies based on limited data, such that there may be significant uncertainty in some areas. As more data become available, the detailed performance attributes included in Table I will be refined, reducing the uncertainty in the estimated performance assessment. Suggested weighting factors for each of the performance regimes and associated attributes are assigned in Table I. The weighting factors included in Table I were defined via 
consultation with an Industry Advisory Committee (IAC) to the AFC National Technical Director, which includes members from nuclear utilities and fuel vendors. Using their individual expertise, the IAC came to consensus on the relative importance of the fuel performance across the five defined regimes (I through V) and the relative importance of the performance attributes ( $a, b$, c, etc.) defined within each regime based on the leading design objectives for ATF. Economic evaluation of the proposed ATF concepts was specifically omitted from the technical assessment table such that adherence to the technical criteria can first be evaluated without being overshadowed by economic factors that have high uncertainty early in the development of new materials and fabrication techniques. A follow-on paper will address the corresponding economic evaluation of ATF concepts.

Assessment scores from Table I can be totaled into overall benefit and vulnerability scores for the reviewed fuel system concept through application of Eqs. (1) and (2):

$$
\text { Score }_{\text {Benefit }}=\sum_{i=I}^{V} w_{i} \sum_{j=a}^{h} w_{j}(\text { Benefit })
$$

and

$$
\text { Score }_{\text {Vulnerability }}=\sum_{i=I}^{V} w_{i} \sum_{j=a}^{h} w_{j}(\text { Vulnerability }),
$$

where

$$
\begin{aligned}
w_{i}= & \text { fractional regime weighting, where } i \text { is the } \\
& \text { index for the performance regime that ranges } \\
& \text { from I through V } \\
w_{j}= & \text { attribute weight within the regime, where } j \text { is } \\
& \text { the index notation for each attribute. As noted } \\
& \text { in the "Identifier" column of Table I, a different } \\
& \text { number of attributes are noted for each regime, } \\
& \text { ranging from a through } \mathrm{h} .
\end{aligned}
$$

The benefit and vulnerability scores should not be summed but should instead be used as independent assessments of the anticipated performance of the reviewed concept.

\section{IV.B. Evaluation Approach}

The general evaluation approach is designed to identify both benefits and vulnerabilities for each concept, where vulnerabilities also encompass development risks. Using Table I, the performance of each fuel system concept is ranked on a scale of 0 to \pm 5 for each identified attribute, where benefits are given a positive score and vulnerabilities are given a negative score. A score of 0 would indicate no notable change from the current fuel system; i.e., evaluation of $\mathrm{UO}_{2}$-zirconium alloy would result in an overall score of 0 for both benefits and vulnerabilities. A score of +5 in the benefits column would indicate a significant benefit/improvement, or anticipated improvement based on the available data, relative to the current system. A -5 in the vulnerabilities column would indicate a significant data gap (development risk due to unknown behaviors) or a potential issue for the indicated performance attribute. As an example, a vulnerability could be a known operational issue that results from a particular fuel system behavior or requirement, such as a known incompatibility between the cladding and the reactor coolant. If a specific property or behavior has not yet been measured or tested, or if it is not known conclusively, this would correspond to higher vulnerability and should be scored as such. For attributes that are currently unknown or assumed, recommended actions should then be noted by the TRC to mitigate the associated risk. The justification for the specific assessment will also be noted for clarity and to allow better parsing and delineation of the data across multiple concepts.

Scoring of benefits and vulnerabilities is inherently subjective in nature. The purpose of establishing a range of possible scores from 0 to \pm 5 is to allow for more discretization by the review committee that will be necessary in prioritizing the various concepts. Scoring of benefits and vulnerabilities separately ensures that technologies can easily be parsed into categories of moderate benefit-low risk; moderate benefit-high risk; significant benefit-low risk; and significant benefit-high risk (see Table III).

Table I attempts to list key considerations under each performance regime and the associated performance attributes for those regimes. This list is not exhaustive but is intended to identify the major contributors/considerations to the identified regime. Some of these items may need to be modified for particular plant designs. In the absence of a specific plant design, which would include details of emergency response systems applicable to accident performance, these assessments must be made on a general basis. Assessments can and should be refined when considering the use of a new fuel system in a specific plant.

Table I can also be applied at varying stages of development. The level of uncertainty in each of the performance attributes would be expected to decrease at each evaluation stage, allowing quantitative estimates for some of the behaviors of interest as more property data become available. To continue with the above example of a highrisk, potentially high-payoff technology, the vulnerability score and number of recommended actions would be 
TABLE III

Summary of How Technologies Can be Parsed into Categories Based on Evaluation Results

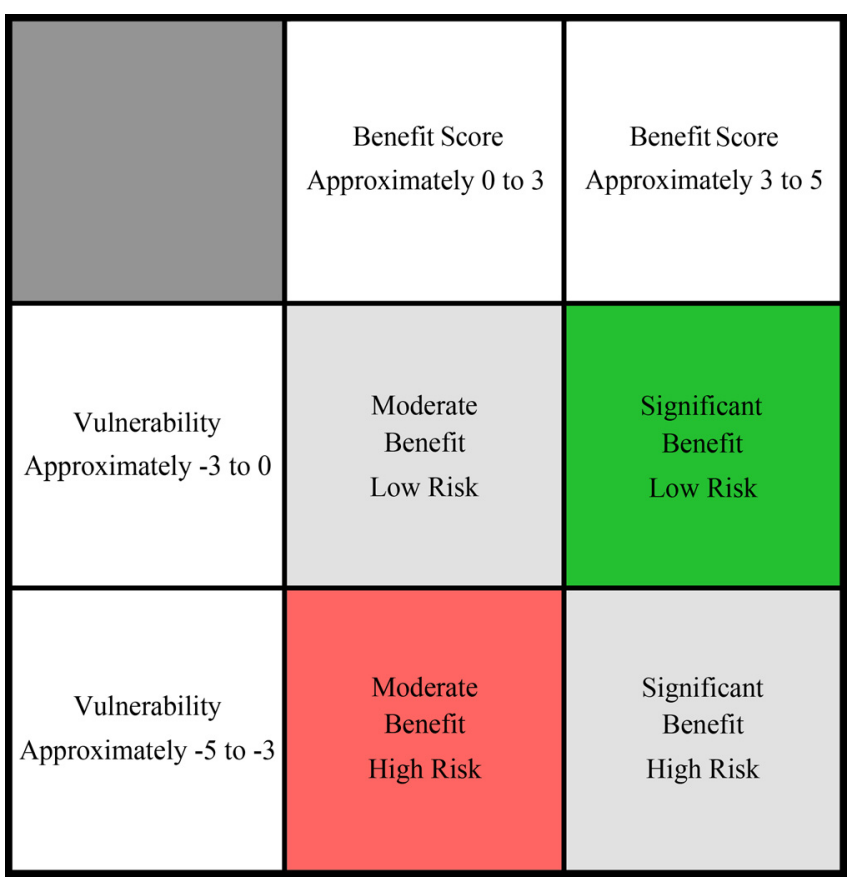

expected to decrease between subsequent reviews to allow a more informed decision to proceed (or not proceed). Note that there is also provision for "off-ramps" prior to the TRC review should a concept design or specific material demonstrate that it cannot meet the minimum performance requirements during the fundamental scoping tests (step 2a) or core-level analysis (step 2b).

The overall benefits and vulnerabilities scores, calculated using Eqs. (1) and (2), for each technology will inform a ranked, prioritized list of candidate technologies. The two columns must not be summed, which could allow perceived benefits to overshadow possible vulnerabilities but should instead be maintained as separate scores at all stages of evaluation. The TRC may choose to develop two ranked lists, one for near-term technologies, fitting within the defined 10-year development window, and a second for longer-term technologies that appear to have a significant benefit at this early development stage but are unlikely to meet the defined development time frame (currently high vulnerability). The number of technologies selected to proceed for additional testing and development will be dependent on budget availability. It is anticipated that a reduced number of technologies will continue development beyond the initial feasibility assessment and into phase 2 development. Upon completion of phase 2, one or more LFRs or LFAs would be fabricated for industry testing in a currently operating commercial LWR.

\section{IV.C. Independent Technical Review}

The evaluation of proposed concepts will be conducted by an independent technical review committee (TRC) at the end of the feasibility assessment phase. The TRC comprises technology experts selected based on their knowledge of the technologies under review, reactor operations, and fuel fabrication plant operations. The cross section of experts includes experience in the areas of materials (metals and ceramics), neutronics, thermal hydraulics, and severe accidents to enable assessment of the technology feasibility for near-term development of the ATF design concepts.

The TRC will provide independent assessment of the technology feasibility for near-term R\&D of candidate ATF design concepts and prioritization of those concepts and will also provide input to prioritization of concepts requiring longer-term development. Following initial assessment of a concept's ability to pass the go/no-go criteria described in Sec. II.C, Table I can be used to aid the panel in quantitatively ranking the potential performance of multiple concepts across the fuel life cycle and range of potential operating conditions. Quantitative ranking will utilize the qualitative assessment of each of the defined performance attributes in combination with the recommended metrics weighting factors.

The TRC was provided an opportunity to review the recommended regime and attribute weighting factors to verify acceptability and to identify additional performance attributes for consideration. This input has been incorporated into Table I. Weighting the performance attributes ensures that the most important behaviors are given greater significance should they be scored as having a high benefit or vulnerability, which allows the resultant concept prioritization to be more meaningful. The TRC will review currently available data and analysis results provided by each of the concept design teams to make a qualitative assessment of the relative benefits or vulnerabilities associated with the candidate design for each performance attribute relative to the specified performance regimes (I through V). Missing information (e.g., data not yet available) is also considered to be a vulnerability and will be scored as such.

The concepts presented to the review committee may be at varying stages of development. It is unlikely that any of the concepts will have been fully characterized upon commencement of the review. As noted previously, the goal for the review at the end of phase 1 is to have sufficient confidence in the assessment results to estimate the potential for success of a concept and to make preliminary estimates on the time and budget that may be required to develop the concept to maturity. 


\section{CURRENT STATUS AND PATH FORWARD}

The United States is currently in the feasibility assessment phase of ATF development. Initial expert review of each concept (step 1 in Fig. 2) was conducted via internal program review and consultation with an independent advisory committee to arrive at the current list of technologies supported via DOE funding. ${ }^{9}$ Program leaders from DOE and the national laboratories have rigorously reviewed concepts proposed by national laboratory participants, industry (via proposals made to a DOE funding opportunity announcement on ATF), and academia (via Nuclear Energy University Program Integrated Research Project proposals) to result in the current set of ATF development teams; awards were made to industry and university teams in 2012 to support development of multiple ATF concepts. ${ }^{10}$ The process outlined in this paper helped guide an independent technical review and prioritization of ATF concepts that was conducted in January 2016. Results of this independent review are now being used as input to DOE in the selection of concepts for phase 2 development. Phase 2 development activities will commence in FY2017.

The technical evaluation methodology described in this paper is applied to aid the assessment of the anticipated performance and safety of proposed ATF concepts relative to the current $\mathrm{UO}_{2}$-zirconium alloy system. Rather than focus on individual properties, the approach considers the confluence of properties that results in a particular behavior during all phases of possible operation and also considers challenges associated with fabrication of each concept. Evaluation tables completed for each concept provide a high-level overview of each new concept relative to one another, highlighting expected benefits and vulnerabilities. This information can be translated into the risk/ benefit ratio for each concept and can be linked to the near-term versus long-term nature of the concept development. The intended goal of this exercise is to inform concept prioritization, such that the most promising ATF design option(s) can continue to be developed toward qualification.

Details on the concepts currently under development can be found in Ref. 10. This paper does not present review results for any of the concepts, as these details are not yet available. This paper is intended to be broadly applicable and should not be perceived to favor any one concept over another. The limited scope of this paperfocusing only on the evaluation approach - is intended to provide an archival publication for concept development teams to reference as each team prepares data and a TIP for each fuel system concept, within the United States and in the broader international community.

\section{Acknowledgments}

This work was supported by the DOE-NE under DOE Idaho Operations Office contract DE-AC07-05ID14517 and was performed on behalf of the FCRD AFC. Significant contributions have been made to the metrics development effort by a number of individuals across the DOE complex.

\section{References}

1. S. M. BRAGG-SITTON et al., "Enhanced LWR Accident Tolerant Fuel Performance Metrics," INL/EXT-13-29957, Idaho National Laboratory (2013).

2. R. YOUNGBLOOD and C. SMITH, "Technical Approach and Results from the Fuels Pathway on an Alternative Selection Case Study," INL/EXT-13-30195, Idaho National Laboratory (2013).

3. W. J. CARMACK, "Technology Readiness Levels for Advanced Nuclear Fuels and Materials Development," INL/EXT-14-31243, Idaho National Laboratory (2014).

4. M. SNEAD et al., "Technology Implementation Plan: ATF FeCrAl Cladding for LWR Application," ORNL/TM-2014353, Oak Ridge National Laboratory (May 2014).

5. Y. KATOH et al., "Systematic Technology Evaluation Program for $\mathrm{SiC} / \mathrm{SiC}$ Composite-Based Accident Tolerant Fuel Cladding and Core Structures," ORNL/TM-2014-210, Rev. 1, Oak Ridge National Laboratory (Jun. 2014).

6. L. A. BRAASE, "Enhanced Accident Tolerant LWR Fuels National Metrics Workshop Report," INL/EXT-13-28090, Idaho National Laboratory (2013).

7. L. A. BRAASE and S. M. BRAGG-SITTON, "Advanced Fuels Campaign Cladding \& Coatings Meeting Summary," INL/EXT-13-28628, Idaho National Laboratory (2013).

8. Proc. Workshop Increased Accident Tolerance of Fuels for Light Water Reactors, Issy-les-Moulineaux, France, December 10-12, 2012, NEA/NSC/DOC(2013)9, Organisation for Economic Co-operation and Development $/ \mathrm{Nu}-$ clear Energy Agency (2013).

9. R. MONTGOMERY et al., "Industry-Valued Design Objectives for Advanced LWR Fuels and Concept Screening Results," Proc. LWR Fuel Performance Mtg. (Top Fuel 2013), Charlotte, North Carolina, September 15-19, 2013, American Nuclear Society (2013).

10. S. M. BRAGG-SITTON, "Development of Advanced Accident-Tolerant Fuels for Commercial LWRs," Nucl. News, 57, 3, 83 (2014). 